\title{
Efficacy of botulinum toxin type $A$ in new daily persistent headache
}

\author{
Roderick C. Spears
}

Received: 23 September 2008/ Accepted: 1 October 2008/Published online: 25 October 2008

(c) Springer-Verlag 2008

\section{Dear Editor,}

New daily persistent headache (NDPH) was first described by Vanast [1] in 1986 as a benign form of chronic daily headache $(\mathrm{CDH})$. Vanast described NDPH as a headache that would improve without therapy, but as most headache specialists know, NDPH can be one of the most refractory forms of $\mathrm{CDH}$ to treatment. The diagnostic criteria for $\mathrm{NDPH}$ based on the last edition of the International Headache Society (IHS) Classification of Headache Disorders [2] is as follows: headache for $>3$ months, daily and unremitting from onset, with at least two of the following pain characteristics: bilateral location, pressing/tightening quality, mild or moderate intensity, not aggravated by routine physical activity. Also both of the following: no more than one of photophobia, phonophobia, or mild nausea, and neither moderate nor severe nausea nor vomiting; finally, not attributed to another disorder.

The prevalence of $\mathrm{CDH}$ from population-based studies in Asia, Europe, and the US is about 4\% [3]. NDPH is rarely stratified from the data in epidemiologic studies focusing on CDH. Bigal et al. [4] found $10.8 \%$ of 638 patients with $\mathrm{CDH}$ in a headache specialty clinic had NDPH. Koenig et al. [5] found that $13 \%$ of a pediatric $\mathrm{CDH}$ population from selected pediatric headache specialty clinics had NDPH and Castillo et al. [6] found a prevalence of $0.1 \%$ of NDPH in 2,252 subjects in Spain with an overall prevalence of $4.7 \%$ for CDH. Rozen [7] published the first study demonstrating effective treatment of NDPH in five patients with gabapentin or topiramate.

R. C. Spears $(\bowtie)$

Center for Headache and Pain, Cleveland Clinic Foundation, 9500 Euclid Avenue T33, Cleveland, OH 44195, USA

e-mail: spearsr2@ccf.org
I present the case of a 67-year-old man with NDPH that has been completely responsive to botulinum toxin type A for 1 year. He reported the onset of headache in June of 2006. He reported the headache began in the occipital area bilaterally and radiated to the vertex. He reported the duration to be constant, and described the pain as sharp at times, also dull, achy, and pressure like. He reported no known triggers and denied photophobia and phonophobia. He rated the pain a $6 / 10$ on the severity scale most days.

Physical examination and testing of this patient failed to reveal any secondary cause for the headache and I diagnosed him with NDPH.

In August 2007, the patient received his first set of injections of botulinum toxin type A, 100 units in the following muscles: glabellar, frontalis, temporalis, suboccipital medial and lateral, semispinalis, splenius capitus, and trapezius. When he returned in November of 2007 for the second set of injections, he reported becoming headache free 4 days after the first set of injections and remaining that way for 8 weeks. He reported the headache returned was unchanged and remained daily. He received a second set of injections, 100 units, in the same locations and returned to the office in January 2008. At that time, he reported becoming headache free again within 4 days of treatment and remaining that way until approximately 10 days prior to that appointment. He also reported less severity of pain although the headache had returned. He received his third round of botulinum toxin type A when he returned to the office in May 2008. He reported being completely headache free for 10 weeks and again with less severity, reporting a level of $3 / 10$ for his headache when it returned.

Therapy of primary headache disorders or pain disorders with botulinum toxin A is relatively new. Analysis of the available studies and experience with botulinum toxin A in 
the treatment of primary headache disorders shows that a general efficacy of this therapy cannot be postulated to date. This is due to conflicting results in multiple studies [8]; however, in clinical practice wider series of patients with $\mathrm{CDH}$ received substantial benefits from botulinum toxin type A [9].

To my knowledge, this is the first case report of the demonstrated efficacy of botulinum toxin type $\mathrm{A}$ in the treatment of NDPH. In conclusion, botulinum toxin A may be a sufficient therapy for specific subgroups of patients with primary headache disorders. In the case of NDPH, a well designed and controlled pilot study using botulinum toxin $\mathrm{A}$ is needed for validation of my finding in this report. This can be performed in a blinded double dummy study, which is very difficult to design. It is important, however, to test the validity of this therapy in such a refractory headache disorder as NDPH.

Conflict of interest None.

\section{References}

1. Vanast WJ (1986) New daily persistent headaches: definition of a benign syndrome. Headache 26:317
2. Headache Classification Committee of the International Headache Society (2004) The international classification of headache disorders, 2nd edn. Cephalalgia 2004; 24 (supp1):1-160

3. Silberstein SD, Lipton RB (2001) Chronic daily headache, including transformed migraine, chronic tension-type headache and medication overuse. In: Silberstein SD, Lipton RB, Dalessio DJ (ed) Wolffs Headache and other head pain. Oxford University Press, Oxford, pp 247-282

4. Bigal ME, Sheftell FD, Rapoport AM et al (2002) Chronic daily headache in a tertiary care population: correlation between the International Headache Society diagnostic criteria and proposed revisions of criteria for chronic daily headache. Cephalalgia 22:432-438

5. Koenig MA, Gladstein J, McCarter RJ, The Pediatric Committee of the American Headache Society, et al (2002) Chronic daily headache in children and adolescents presenting to tertiary headache clinics. Headache 42:491-500

6. Castillo J, Munoz P, Guitera V, Pascual J (1999) Epidemiology of chronic daily headache in the general population. Headache 38:497-506

7. Rozen TD (2002) Successful treatment of new daily persistent headache with gabapentin and topiramate. Headache 42:433

8. Evers S, Rahmann A, Vollmer-Haase J, Husstedt I-W (2002) Treatment of headache with botulinum toxin $\mathrm{A}-\mathrm{a}$ review according to evidence-based medicine criteria. Cephalalgia 22:699-710

9. Farinelli I, Coloprisco G, De Filippis S, Martelletti P (2006) Longterm benefits of botulinum toxin type A (BOTOX) in chronic daily headache: a five-year long experience. J Headache Pain 7:407-412 